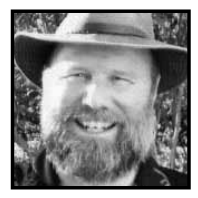

\title{
Steppingstones to Appreciating the Importance of Play in the Creative Act
}

\author{
Joe Norris, Brock University
}

\section{ABSTRACT}

This paper documents how the literature on creativity has inspired a professor to live and teach creatively. Through a weaving of stories with the literature, the paper demonstrates that praxis is achievable and can be fun! It is hoped that the stories will inspire the readers to take risks and become more playful and creative in all aspects of their lives.

And each must fashion, ere life is flown, A stumbling block or a stepping-stone

R. L. Sharpe (1948, p. 306)

\section{Prologue}

$\mathbb{R}$ uilding upon Aoki's claim (2005) that teachers live in the zone of tensionality between the curriculum-as-planned (the hypothetical) and the curriculumas-lived (the experience), this reflective paper first articulates how the literature on play and creativity has provided me with theoretical steppingstones upon which I have built my practice. It then provides a few concrete stories that serve as exemplars of how these influences have inspired me to live/teach/perform playfully. The aim is to provide a collage or buffet of abstract thoughts and concrete actions from which readers can choose morsels to their own liking that will enable them, if 
they choose, to counter the hegemonic position of "work" and restore the work/play balance so necessary to our existence.

Robinson (2009) believes that we are taught out of creativity and Wagner (2012) promotes classrooms in which "intrinsic motivation and creative-thinking skills are far more essential than mere technical knowledge" (p. 57). I concur. It is my belief that the over-instrumentalization of the current educational system has created an ethos of convergent learning that desires/demands a predetermined answer/outcome and that the divergent nature of creativity, imagination, and play is systemically discouraged. The aim of this paper is to join with Robinson, Wagner, and others in promoting an environment of play both within and outside of the educational system.

\section{Act 1: Artistry-as-Inspired}

Research at the University of California at Berkeley regarding key insights that lead to successful scientific discoveries found in interviews with scientists that the main activity that seemed to influence successful results was play. The more these scientists were able to enjoy light, seemingly off-purpose games and activities while engaged in research, the greater were their successes at breakthrough discoveries. (Cloke \& Goldsmith 2002, p. 11)

Whether one works, plays, or studies in the arts, humanities, sciences, or business, "play" plays a vital role in enabling acts of creation and co-creation. As described in the quote above, play is a disposition towards a task that fosters thresholds of possibilities, from which fresh ideas can emerge. Neilsen (2002) defines such a threshold as a "liminal space... a waiting space, a green room" (p. 208). Play, then, requires patience as one experiments with existing ideas until new ones emerge. The "when" cannot be dictated by a deadline or strategic plan. Whether it is something novel that seems to come from nowhere or is something that we knew but didn't know that we knew, play acts as a midwife facilitating new insights, inventions, practices, treatments, or artistic pieces.

Harman and Rheingold (1984) remind us that the root of imagination is "magi," meaning from another place. The Magi in the Christian faith came from another place and (magi)cians bring rabbits from another place through empty hats. The i(mage)s that we see through our eyes initiated elsewhere and our i(magi)nations create things that seem to come from a place unknown. To be creative, means to be in a state of openness to the unknown, a place of possibilities, a place that a playful environment fosters. Harman and Rheingold call this waiting, "incubation," comparing 
it with a computer going offline to work in the background, as other tasks are done. But the creative process is much more that waiting. Gordon (1961) claims that the perspiration stage occurs prior to incubation, as one gathers ideas and materials from other sources and commences to work/play with them in an attempt to have a breakthrough thought and/or new creation. A lot of preliminary work is necessary before one waits.

McGuinness (2007) claims that if previous "work" (perspiration) has occurred prior to the waiting, the stage is incubation; if not, it is procrastination, as the work must come first. I partially agree. Root-Bernstein and Root-Bernstein (2001) discuss how a "playful" spirit underpinned the "work" of the scientist Alexander Fleming who was infamous for his ability to play both socially and at work. "Nor did Fleming confine his playful spirit to after-hours only. He played at work - or, more accurately, he played with his work" (p. 247). Fleming drew pictures on agar plates and while the scientific community initially ignored him, these seemingly frivolous activities were the initial stages of his research with penicillin.

Sometimes play is the prerequisite not only to incubation but also to perspiration. Most often I need to play myself into the mood of creating/writing. Drama teachers call these warm-ups. Once there, I can get down to the task at hand. I often take this stance when I become blocked as a writer. I leave the task and "play" a computer game or tidy my desk, or... When I return refreshed, the flow, most often, returns. In my early years I considered this "goofing off" but through the insights of Harman and Rheingold, I now embrace "play" as natural and healthy aspect of the "work" that I do. It creates a healthy waiting space. The perspiration, incubation, and illuminations stages may not be as linear as the theory suggest. The act of perspiration can take many forms and need not be restricted by rigid methodologies and techniques. Root-Bernstein and Root-Bernstein's book, Sparks of Genius and Harman and Rheingold's (1984), Higher Creativity document many such cases of playing in the arts and sciences. Intuitively playing around with things can be serious work (perspiration).

Cottrell (1979) blurs the line between play and work with the phrase, "Play is the work of the young child" (p. 2). Implicit within the statement is a trace to Derrida's concept of logocentrism (Culler, 1982). The English language is based upon binary opposites with one term considered dominate and/or positive and the other subordinate and/or negative. In addition to denotative meanings of words, within them are previously embedded cultural biases. Day is preferred over night, with the perception that evil happens most often in the dark. Our culture has a longstanding history of considering males dominant and only within the last century and one-half has some 
semblance of equality emerged. In research, objectivity (male) has been valued over subjectivity (female) and work, not play, is preferred in schooling. The list exploring the hegemonic structures with our language can be a long one, much longer the meager example below.

\section{Table 1}

\section{Dominant and Subordinate Structures With Language}

DOMINANT

(or Good) Hegemonic

Day

Male

Objective

Reality (Fact)

Work

Create

Rational

Certainty

Science

Left Brain
SUBORDINATE

(or Bad)

Night

Female

Subjective

Fantasy (Fiction)

Play

Destroy

Liminal (not in spell checker)

Uncertainty

Art

Right Brain

To make the concept of logocentrism explicit, each year, I ask one of my students to make a paper airplane and then throw it. After picking it up, I first talk about how creative that act was, outlining the sleek design and the ability to reshape a flat piece of paper so that it could fly. Then, I unfold the plane, commenting on the act's destructive nature and how difficult it will be to take notes on it, the paper's intended purpose. The problem is embedded within our language. We often choose to place value on one aspect of our actions, our desired one, ignoring its other characteristics. But Shiva is not only the goddess of destruction-she is also the goddess of transformation and rebirth. In every act of destruction there is an act of creation and vice versa. I relate how a logocentric analysis can be applied to the work/play dichotomy.

Musicians play instruments, athletes play sports, and in drama, as young children, we may have done role-plays for our personal enjoyment, but, at times, we rehearse them to show to others and call that product, a play. Our educational system reinforces the subordinate position of play with an implicit bias where subjects that use the word "play" are not considered core but designated as optional. Play is a 
misunderstood state. The hidden curriculum (Flinders, Noddings, \& Thornton, 1986) of schooling predominately creates an ethos away from the arts and creative acts in mathematics and the sciences. The hegemony of standardized testing practice that seeks convergent responses discourages the "thinking outside-of-the-box" or the divergent mentality so necessary to play and creativity. There is a lot of "collateral damage" (Nichols \& Berliner, 2007) with creativity being but one example.

Phrases like, "Stop playing around," "I'm just playing," and "Get back to work" demonstrate the inherent privileging of work. Black (1987) confronts this by calling for the abolition of work by providing a counter hegemonic discourse. Wing (1995) found that children categorized tasks directed by another as work (extrinsically motivated) and that play was more autonomous (intrinsically motivated). Refuting Cottrell and others, she claimed that, "In contrast to the early childhood maxim 'play is the work of the child,' in children's minds, play is not work" (p. 227). For these students play and work were considered distinct, with the power of logocentrism underlying the difference. Our young learn quickly the cultural denotations of words.

This socio-linguistic categorization, however, ignores the use of play in one's early years. When referring to infants, we claim that they are "playing with their hands." The term "work" is seldom used to describe the development of these psychomotor skills. Infants experiment with their bodies until their desired actions match their intents. The same happens with language development. An infant's babbling is a form of play where the child experiments with sound until she/he finds those that match the culture in which she/he was born. Children play naturally with no imposed external expectations. Play, then, could be considered synonymous with (experi) ment and (experi)ential learning. Through natural living our young play around until they discover things worth keeping.

This occurs often in the arts. Artists and students experiment with sounds, images, and gestures as they explore and assess their emergent compositions. In fact, they form hypotheses, immediately test them and then make adjustments. Their work/play is similar to an immediate bio-feedback loop. Those in the arts apply the scientific method daily as they experiment and revise as they go. Interestingly, this is most often labeled play, not work; art, not science. I contend that the scientific method is frequently employed in every art form and class although it is not labeled as such. Like work and play, with creativity, there is also a blurring of art and science.

Play and work, then, appear to function more as adverbs than verbs. They provide our attitudes toward the tasks at hand. Any task can be categorized with 
either of these two terms. One can "work" the piano or "play" with numbers. Imagine an accountant leaving the house in the morning saying, "I'm off to play." While this may be more accurate, it runs against our cultural beliefs. The work world rulz.

Play is also valued by engineers who often use the term play in reference to the flexibility of a structure. A bridge will collapse in the wind without some flexibility and a building will topple in an earthquake if there is not enough play in its design. Rigidity can be a dangerous thing in the physical, social, and educational worlds.

Some business literature also supports the value of play. Freiberg and Freiberg (1998) in their history of Southwest Airlines discuss the importance of humor in the workplace. They report practical jokes and playful incidents concocted by employees. They claim that,

These people are scrupulous about working hard and zealous about having fun-so much so that many people want to know, "Who these nuts are?" they are impassioned about treating each other like family... many outsiders think they are hokey and unquestionably nuts. (p. 3)

Southwest Airlines even has a humor manifesto. Similar to Fleming, Southwest Airlines encourages employees to play at work. The same attitude is found at the Pike Place Fish Market (Lundin, 2000; Lundin, Christensen, \& Paul, 2003). Instructional management programs have been designed based upon these fish mongers' abilities to play at work.

Bakke (2005) also recognizes the value of an intrinsically motivating workplace, a place in which people conduct tasks because they want to.

Winning, especially winning financially, is a second-order goal at best. Working according to certain timeless, true, and transcendent values and principles should be our ambition. A major point of this book is to suggest a broader definition of organizational performance and success, one that gives a high priority to a workplace that is filled with joy for ordinary working people (p. 18).

"Work"-places and schools need play and flexibility so that those who dwell in such places find them humane. To be human is to have humor, the ability to laugh. It defines us as a species. We are called to be creatures of joy in all aspects of our lives. Part of that joy comes from the pleasure of creating things (Buber, 1947). The call to 
create is natural, our birthright. I (1989), referencing the Bible as a literary and/or religious text, claim that if people were made in the creator's image and the first image of the "creator" is that of a creator, then it is our right and responsibility to create.

But the ability to play and create is fraught with inter and intrapersonal obstacles. Robinson (2006), claims that "If you are not prepared to be wrong you will never come up with anything original" and I believe that our school system places more obstacles in the way of, than steppingstones toward, the creative act. Over the years I have learned to unlearn the specter of the judge and just do (Madson, 2005). I do bring in the judge/editor but at a much later date. Over time I have begun to realize that having the judge present too early inhibits the play so necessary to the creative act.

I remember taking a full-day mask workshop with Richard Pochinko in 1976 (circa) and being asked to lie on my back and with my eyes closed and paint the inside of the imaginary box in which I was contained. At first, I was careful, making certain that I got everything right when suddenly I was struck with the idea that the workshop leader had no idea what I was doing. My movements became freer and the colours more vivid. I switched to a roller in one hand and a brush in the other. I had fun painting inside and outside of the metaphorical lines.

Nachmanovitch (1990) believes that the biggest obstacle to creativity is fear of the judge and in Pochinko's workshop my externally fostered internal judge had disappeared. The paint flowed (Csikszentmihalyi, 1990) freely as the cork to my imagination was released. Through twelve years of schooling I had learned to get it right based upon ever-watchful eyes. "Please the teacher" was deeply engrained into my psyche. The workshop was a turning point for me. I consider this event, at the age of 24 , my creative birth date. It was on this day that I discovered the "courage to create" (May, 1975), way too late by my standard. From then on I embarked on a path of trying to reclaim my playful self both in and out of school and over the years many readings and workshops assisted me in appreciating the importance of play and utilizing it in my teaching, artistry, and living. This became my self-designed curriculum.

Fantasy is also a misunderstood component of play; sadly it too is often used pejoratively. It is not the "real world" as skeptics would argue. Prospero's claim that "We are such stuff as dreams are made on; and our little life is rounded with a sleep" (Shakespeare, 1972a, p. 1563) is marginalized. When we are told not to daydream, those "seemingly off-purpose games and activities" are discouraged, play ceases to be, and potential creativity is lost. 
One steppingstone in reestablishing the value of play is reclaiming the role fantasy in our lives. Harman and Rheingold (1984) report that Elias Howe's breakthrough with the invention of the sewing machine came in the form of a dream. We ARE the stuff of dreams. The chairs that we sit on are based upon the imaginations of thousands of people from the first person who sat on a stone, to the one who found wood to be softer, to the person who carved wood to better shape her/his behind, through those who worked with metal, fabric, and synthetics and the designers who created the multitude of shapes and styles. Each day we actually sit on a conglomerate of fantasies. Dreams, while of value in and of themselves, can also have utilitarian purposes.

I do most of my writing after awaking from a deep sleep and often find that I write best (like now) when I first wake up. It is this state where my brain free flows and the judge is suspended for a much later future edit (also done). I call it the "twilight zone" (Norris \& Greenlaw, 2012), a time when I metaphorically paint within my imaginary box. That twilight place is one of my thresholds to the fantasy world, a place where I can imagine. Such places need fostering and as artists we have learned to create our own thresholds and as teachers of the arts we assist others in finding/ creating theirs.

While common practice is to distinguish work and play, I encourage the conceptual collapsing of this binary opposite, to move beyond Wing's observation and create a world in which we do things for self (play) and for the Other (work). Such is the call of Buber (1958). One balances self in the world of Others when one attempts to achieve an I-Thou relationship. One achieves joy, not merely from the act of playing, but with the recognition that such joy can be and most often will be shared with others. Play for the self alone can lead to self-centeredness. Unlike Black, I do not call for the abolition of work but for removal of its hegemonic position. With work to balance play, one becomes centered-in-self, recognizing that Others are l's to themselves. The restoring of the balance of work and play, in addition to epistemological and ontological reasons, has an axiological one. We share the sandbox, classroom, staffroom, and playground.

\section{Act II: Artistry-as-Lived}

Kopp (1972) believes that we can learn vicariously by listening to the stories of others as we resonate with certain aspects and incorporate them into our own beliefs and actions. Barone (1990) calls such resonance a conspiracy where the reader breathes (spires) con (with) the narratives presented. The following vignettes provide 
just a few concrete examples of how I have attempted to live and teach playfully with the hope that these stories may serve as steppingstones for others.

\section{Appreciation of accidents.}

Nachmanovitch (1990) cites Miles Davis' slogan, “Do not fear mistakes. There are none" (p. 88). He claims that a pearl is made from a grit of sand and that we must learn how to make pearls. Long before I read this quote but shortly after I had taken the Pochinko workshop, I found myself cast as Professor Strychnine in the pre-musical version of Spring Awakening (Wedekind, 1912). After one scene we exited stage right and picked up umbrellas, ran quickly under the stage and back up the other side to enter after a short scene between the two. During a dress rehearsal the umbrella stuck upside down, forming a bowl instead of an awning. Rather than delaying my entrance to fix it, I went with it. In this production the professors all wore masks, so the director had to query who had the upside down umbrella. I raised my hand and he responded, brilliant, keep it. During a subsequent rehearsal, the rain came and the umbrella filled with water. This bizarreness added to the macabre nature of this funeral scene.

Had I tried to remove this metaphorical grit, the scene would have missed these elements. Since then, I have come to appreciate mistakes and advocate the looking for pearls. Mistakes can be regarded as unforeseen play that invites us to respond differently, like a tree to a summer breeze. Do we resist or accept?

In directing a scene about the many responsibilities of a teacher we piled a number of boxes in an actor's arms. In one rehearsal, they toppled. From then on, we made them topple. The acceptance was, in part, due to my previous experience with mistakes. I have come to recognize that creativity is not always deliberate, that one steppingstone towards play is the embracing of mistakes and, when appropriate, turn them into pearls.

\section{Risk taking in teaching.}

Nachmanovitch (1990) also claims that creativity is not about having unlimited resources but about working with the givens. Building upon this concept, I decided to take a risk/experiment and try something new in my teaching, uncertain of the outcome. I asked the students to wander the campus and return with a collection of "clean garbage." I explained the task no further. They returned with leaves, pop cups and everything in between. I then put them into groups and asked them to create the balcony scene from Romeo and Juliet with their collection and then explain their choices. The result exceeded my expectations. They played outside of the cliché 
and found dimensions of the scene that expanded our collective understanding of the play.

The students working with their givens created something original. Had they been told to find things to create the scene, their creativity would have been reduced to what was already known. Not knowing the second task actually increased the potential for something new, as the known can be an obstacle in and of itself. This also provided an insight for my teaching/planning. From the experience I concluded that it is not always best for teachers and students to know what will emerge. We, too, must model risk taking and take leaps of faith. Visions can be restrictive. By keeping ourselves in the dark, we expand our thinking by playing with uncertainty. Since this experience, I have created many lessons with this discovered principle.

\section{The acceptance of the intuitive, liminal, and dreams.}

I was asked by a colleague to give a guest workshop on The Sandbox (Albee, 1988) to her high school drama class. Again, I tried something new. I asked the students to bring in a collection of magazines and tear out phrases and pictures that intuitively spoke to them in a way that related to the play. I joined in the activity and two of the images that I chose were a large fork and a man in a wheelchair. Once we each had a sizable assortment, I asked them to assemble their collection into a collage and find a relationship among what they had chosen.

For my collage, as I placed the wheelchair on the fork I experienced an "ah ha" moment. The play is about how the young eat their elders. Student comments were as insightful. The final part of the lesson had the students not only share their collages but also tell us, based upon their collages, how they might direct the play or design its set. Their articulation of their understandings of the play went well beyond what would be typically expected. Their openness to playing with another medium was an indirect intuitive route to new meanings.

Harman and Rheingold's (1984) examples of the invention of the sewing machine, the discovery of mathematical formula, and other breakthroughs that emerged from dreams reinforced my belief in the intuitive and I continue to create lessons in which I ask my students "not to think." I believe that we can overthink and shut down relevant parts of the brain that are the wellsprings of great ideas. Too much planning can get in the way of the liminal and throughout my teaching, I encourage my students to play with their ideas in different ways, to take risk and leaps of faith. Most often this results in better work/play. My mantra is, "I don't know where I'm going but I do know how to get there." 


\section{Trusting play.}

I recently changed an activity that I do with a course of graduate students (practicing teachers). Previously, I created five centers, one with puppets, one with hats, one with Orff instruments, one with props, and the fifth was my computer with iTunes open. I equally divided those assembled into five groups and they took turns going to each station to complete the tasks written on the sheets of paper before them. During the summer of 2012, I eliminated the iTunes and puppets centers and asked three groups to just go to one center and play. As expected, initially, they had a tough time. Slowly they became more animated and genuinely built upon each other's ideas. The group with the props became pirates and invaded the hat group and escaped with some of their booty. The Orff group paraded around clanging their newfound instruments. Frivolous? Absolutely! But they achieved that playful state that was so necessary for us as we researched and wrote a play about the lived-experiences of teachers.

For me, play and creativity is about disposition, a state of being. While knowledge and skills are necessary, they, without a state of playfulness, lack luster. Nachmanovitch claims that we need both technique and freedom from technique and I agree. To be creative is to enter a state where you trust in the act. Madson's (2005) subtitle to "Improv wisdom" sums this state up, "Don't prepare, just show up". While desired, I have encountered various degrees of student resistance, as they have been enculturated into a means-ends (Peattie, 1960) mentality. Many expect certainty and are skeptical of an emergent curriculum.

\section{Zone of proximal development.}

As a result of student skepticism, I attempt to eliminate the fear of the judge; to promote risk taking and to take leaps of faith into the unknown (easier said that done when I am also the giver of grades). Even with third-year undergraduate drama students and after-degree drama education students, there exists a fear of being watched by their peers. Many continue to report that they censor their actions to avoid being thought silly or wrong. Their creative actions are stifled by such a disposition. I search for activities that wean them from such fear.

In one, I have them all in a circle, facing forward. Their arms are outstretched, horizontal to the floor and their hands are folded together. I ask them to raise their thumbs that will serve as batons as they "conduct" the music that I will play. I then ask them to turn out, so they see no one but themselves. As the upbeat music plays I add different isolations: "conduct with elbows, chins, eyebrows, tongues, knees, baby toes, etc." As they conduct the music, they are moving in atypical ways. Eventually, they 
are moving about the room in parallel action (not interacting with one another) and reach high, low, to the left and right as I side-coach isolations, combinations, levels, and directions. I avoid the word, dance.

During the debriefing that always follows, students comment on the gentleness of the progression and that the facing-out enabled them to become comfortable with the exercise. To create a playful atmosphere, as teachers, we must determine both the stumbling blocks and steppingstones. For me, student comfort, relaxation, and trust are essential. I design activities that build upon where they are emotionally (Goleman, 1995) so that I can playfully invite them to other places. Adapting the theory of the zone of proximal development (Woolfolk, Winne, \& Perry, 2006) that tends to focus primarily on cognitive ability, I apply it to the creation of inter and intrapersonal dispositions, systematically removing obstacles and building steppingstones to play. When activities do not succeed it is sometimes due to asking too much too soon.

\section{For/with other.}

In my early years I detested writing. My extroverted side considered the private time required for writing as punishment. My muse was elsewhere. That changed the summer following grade seven. I took the compositions written that school year, read them at a public speaking contest and won. With a sense of audience, creative writing found a purpose. It is no accident that my research work in both playbuilding (Norris, 2009) and duoethnography (Norris, Sawyer, \& Lund, 2012) is collaborative. I think/play/create best with my mouth open in communion with the Other.

As a former teacher of English, I understood the reluctance that many of my students had to writing, and created some opportunities for them to write collaboratively. Photos were distributed to pairs and each, without conferring, was to write a sentence about the photo and pass it to his/her partner. The paper went back and forth with some students creating their best writing in response to the Other. They became each other's muse as they played collaboratively. They wrote for each other. According to Briggs-Myers and McCaulley (1985), seventy-five percent of our population is extraverted. Their best playgrounds/classrooms are interactive ones. It behooves us, as teachers, to create spaces with the recognition that the Other can provide a) a sense of audience so necessary for some as it provides a sense of purpose and b) that some play/create best in the company of others. Removing the hegemony of silence and creating opportunities for collaborative interaction can foster creativity in the majority of our students. 
The importance of surrender (a confession).

It was the last day of classes prior to the December 2012 break. The previous week was a field trip and I was anxious to reestablish a focus so that we could depart with a strong understanding of the play that we were writing, a springboard so to speak, that would propel us into the New Year. I initiated a check-in with students and we commented on the field trip and clarified questions on the assignment due the following week. We did what I ascertained was the appropriate amount of playful activities. After the break I was determined to get to task (work). As the third-year undergraduate students sat in a circle on the floor, I passed out file folders to store our collective thoughts and was ready to begin when I was bombarded with a series of cascading comments,

Can we play a game?

(Students in unison) Yes.

Come on, its Christmas

Etc.

I put the stuffed lobster that I use as a talking stick on the floor and made it my pillow as I laid down in utter capitulation. I mocked tears. My mind raced. "We already had the obligatory warm-up. How dare they! When we get closer to performance, they will complain that we didn't have enough time. They just came back from a break. They should be ready by now!"

They were insistent.

Sure, I said

Can we, really?

Obviously they didn't believe me.

Isn't that what I said?

Yay! (in unison).

One student suggested Pterodactyl, a game that I did not know. It was an elimination game, the type that I seldom favour as these create winners and losers. But by now I was drained and listened.

"Everyone curls their upper and lower lips inward so that their teeth are never seen. Someone in the circle starts looking either to the person to his/her left or right and says, 'pterodactyl'. Each person in turn passes it but if teeth are shown, that person is eliminated. The receiving person can reverse the direction by making a pterodactyl sound." 
Lots of laughter ensued and for about eight minutes we played with about six people remaining. (Try to keep your lips curled in while laughing. It isn't easy.) We then got back to the task with gusto.

The irony of this story is that it happened after I wrote most of this paper. I too am susceptible to the ethos of the task. In my rush, I failed to listen. Sometimes surrender is also a necessary aspect of play. It means "cultivating a comfortable attitude towards not knowing, being nurtured by the mystery of moments that are dependably surprising, ever fresh" (Nachmanovitch, 1990, p. 22). Play requires a deep listening to the moment, accessing the present need and responding accordingly. Walking the talk is more difficult than it looks. Living in the zone of tensionality between the curriculum-as-planned and the curriculum-as-lived is a common state.

The above are but a few of the many experience that I have had in trying to live and teach in a playful way. We all have our stories, and by sharing them we assist others in reinforcing what they already do, provide new pathways to their imaginations, and/ or point out obstacles to avoid. As the Bard says, "The play's the thing... (Shakespeare, 1972b, p. 935) so I conclude with the "F" word, "fun." I had fun writing this piece. Was it work or was it play? I'd say both. For me, the binaries have collapsed.

\section{References}

Albee, E. (1988). The sandbox; and, The death of Bessie Smith; with, Fam and Yam. New York: New American Library.

Aoki, T. (2005). Teaching as indwelling between two curriculum worlds. In W. Pinar \& R. L. Irwin (Eds.), Curriculum in a New Key: The Collected Works of Ted T. Aoki (pp. 159-165). Edmonton: Curriculum Praxis Department of Secondary Education University of Alberta.

Bakke, D. W. (2005). Joy at work. Toronto: Viking Canada.

Barone, T. E. (1990). Using the narrative text as an occasion for conspiracy. In E. W. Eisner \& A. Peshkin (Eds.), Qualitative inquiry in education (pp. 305-326). New York: Teachers College Press.

Black, B. (1987). The abolition of work. Semiotext[e], 13, 15-26.

Briggs-Myers, I., \& McCaulley, M. (1985). Manual:
A guide to the development and use of the Myers-Briggs Type Indicator. Palo Alto: Consulting Psychologists Press.

Buber, M. (1947). Education. In M. Buber (Ed.), Between man and man. London: Kegan, Paul, Trench, Trubner and Company Limited.

Buber, M. (1958). I and Thou (R. G. Smith, Trans.). New York: Charles Scribner's Sons, MacMillan Publishing Company.

Cloke, K., \& Goldsmith, J. (2002). The end of management and the rise of organizational democracy. San Francisco: Jossey-Bass.

Cottrell, J. (1979). Teaching with creative dramatics. Skokie: National Textbook Company.

Csikszentmihalyi, M. (1990). Flow. New York: Harper \& Row.

Culler, J. (1982). On deconstruction. Ithaca: Cornell University Press. 
Flinders, D. J., Noddings, N., \& Thornton, S. J. (1986). The null curriculum: Its theoretical basis and practical implications. Curriculum Inquiry, 16(1), 33-42.

Freiberg, K., \& Freiberg, J. (1998). Nuts! New York: Broadway Books.

Goleman, D. (1995). Emotional intelligence. Toronto: Bantam Books.

Gordon, W. J. J. (1961). Synectics. New York: Harper \& Row.

Harman, W., \& Rheingold, H. (1984). Higher creativity. Los Angeles: Jeremy P. Tarcher, Inc.

Kopp, S. (1972). If you meet the Buddha on the road, kill him. New York: Bantam.

Lundin, S. C. (2000). Fish! A remarkable way to boost morale and improve results. New York: Hyperion.

Lundin, S. C., Christensen, J., \& Paul, H. (2003). Fish! sticks: A remarkable way to adapt to changing times and keep your work fresh. New York: Hyperion.

Madson, P. R. (2005). Improv wisdom: Don't prepare, just show up. New York: Bell Tower.

May, R. (1975). The courage to create. Toronto: Bantam Books.

McGuinness, M. (2007). What's the difference between incubation and procrastination? Retrieved from http://www.wishfulthinking.co.uk/blog/2007/10/23/whats-thedifference-between-incubation-and-pro crastination/

Nachmanovitch, S. (1990). Free play: The power of improvisation in life and the arts. Los Angeles: Jeremy P. Tarcher, Inc.

Neilsen, L. (2002). Learning from the liminal: Fiction as knowledge. The Alberta Journal of Educational Research, XLVIII(3), 206-214.

Nichols, S. L., \& Berliner, D. C. (2007). Collateral damage: How high-stakes testing corrupts America's schools. Cambridge: Harvard Education Press.

Norris, J. (1989). Some authorities as co-authors in a collective creation production. Unpublished doctoral dissertation, University of Alberta.

Norris, J. (2009). Playbuilding as qualitative research: A participatory arts-based approach. Walnut Creek: Left Coast Press.
Norris, J., \& Greenlaw, J. (2012). Responding to our muses: A duoethnography on becoming writers In J. Norris, R. D. Sawyer \& D. E. Lund (Eds.), Duoethnography: Dialogic methods for social, health, and educational research (pp. 89-113). Walnut Creek: Left Coast Press.

Norris, J., Sawyer, R. D., \& Lund, D. (Eds.). (2012). Duoethnography: Dialogic methods for social, health, and educational research. Walnut Creek: Left Coast Press.

Parker, A. (Director). (1982). Pink Floyd: The Wall. United States: MGM/UA Entertainment Company.

Peattie, L. (1960) The failure of the means-ends scheme in action anthropology. In F. Gearing, Netting, R and Peattie, R. (Eds.). Documentary: History of the Fox Project: 1948-1959. Department of Anthropology: University of Chicago. (pp. 300-304).

Robinson, K. (Producer). (2006) Do schools kill creativity? Retrieved from http://www. ted.com/index.php/talks/view/id/66

Robinson, K. (2009). The element. Toronto: Penguin Books.

Root-Bernstein, R., \& Root-Bernstein, M. (2001). Sparks of genius. Boston: Mariner Books.

Shakespeare, W. (1972a). The Tempest. In S. Barnet (Ed.), The Complete Signet Classic Shakespeare. New York: Harcourt Brace Jovanovitch, Inc.

Shakespeare, W. (1972b). Hamlet. New York: Harcourt, Brace, Jovanovich Inc.

Sharpe, R. L. (1948). A bag of tools. In J. D. Morrison (Ed.), Masterpieces of Religious Verse (p. 306). New York: Harper.

Wagner, T. (2012). Creating innovators: The making of young people who will change the world. New York: Scribner.

Wedekind, B. F. (1912). Spring awakening. Philadelphia: Brown Brothers.

Wing, L. A. (1995). Play is not the work of the child: Young children's perceptions of work and play. Early Childhood Research Quarterly, 10(2), 223-247.

Woolfolk, A., Winne, P., \& Perry, N. (2006). Educational psychology. Toronto: Pearson. 


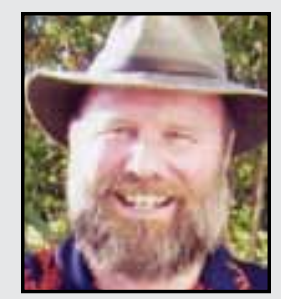

Joe Norris teaches drama as a teaching methodology, theatre for social change, and playbuilding as a research methodology at Brock University. His book, Playbuilding as Qualitative Research: A Participatory Arts-based Approach received the 2011 Outstanding Book Award from the Qualitative Research SIG of the American Educational Research Association. Along with Rick Sawyer he has developed a dialogic form of narrative research. Duoethnography: Dialogic Methods for Social, Health, and Educational Research was released in April 2012 with Left Coast Press and Understanding Qualitative Research: Duoethnography will be published in early 2013 with Oxford University Press.

\section{LINKTO:}

http://www.joenorrisplaybuilding.ca 